\title{
Sodium intake and use of discretionary salt in an Australian population sample
}

\author{
S. L. O'Reilly ${ }^{1}$, M. Brinkman ${ }^{2}$, G. Giles, D. English ${ }^{2}$ and C. A. Nowson ${ }^{1}$ \\ ${ }^{1}$ Centre for Physical Activity and Nutrition Research, School of Exercise and Nutrition Sciences, Deakin University, \\ Burwood, Victoria 3125, Australia and ${ }^{2}$ The Cancer Council Victoria, Carlton South, Victoria 3053, Australia
}

It is now widely accepted that excess salt consumed throughout life causes blood pressure to rise with age and there is clear evidence that lowering salt intake lowers blood pressure ${ }^{(1)}$. There are no recent data on the Na intake of Australians, using $24 \mathrm{~h}$ urinary excretion. The Australian division of the World Action Group on Salt and Health launched their campaign in May 2007 to roll-out a 5-year salt reduction campaign to reduce the population salt intake to $6 \mathrm{~g} / \mathrm{d}$ by 2012 . For Australia, similar to most developed countries, $\geq 75 \%$ of dietary Na intake comes from processed food products and the most accurate assessment of total intake of $\mathrm{Na}$ is through assessment of $24 \mathrm{~h}$ urinary excretion. To determine the effectiveness of any population-wide salt reduction campaign it is important to characterise the population dietary salt consumption. The aim of the present study was to assess Na intakes, through the measurement of $24 \mathrm{~h}$ urinary excretion, and examine the proportion of those who met the dietary targets for $\mathrm{Na}^{(2)}$.

The Melbourne Collaborative Cohort was established in the early 1990s to study prospectively associations between diet and chronic diseases and in 2007-8 a dietary calibration study was conducted with a subset of this cohort providing 24 h urine collections. Participants also provided information on dietary intake and the use of discretionary salt.

\begin{tabular}{|c|c|c|c|c|c|c|}
\hline & \multirow[b]{2}{*}{$\%$ total } & \multicolumn{2}{|c|}{ Males (n 376) } & \multirow[b]{2}{*}{$\%$ total } & \multicolumn{2}{|c|}{ Females $(n$ 408) } \\
\hline & & Mean & SD & & Mean & SD \\
\hline Age (years) & & 64.3 & 6.6 & & 63.7 & 6.1 \\
\hline BMI $\left(\mathrm{kg} / \mathrm{m}^{2}\right)$ & & 28.4 & 4.0 & & 28.0 & 4.9 \\
\hline Urinary $\mathrm{Na}(\mathrm{mmol} / \mathrm{d})$ & & 178 & 66.6 & & 134 & 51.0 \\
\hline Salt (g/d) & & 10.3 & 3.8 & & 7.7 & 2.9 \\
\hline Urinary $\mathrm{K}(\mathrm{mmol} / \mathrm{d})$ & & 88.1 & 30.7 & & 77.0 & 23.9 \\
\hline Salt added at cooking: No & 16 & & & 16 & & \\
\hline Yes & 84 & & & 84 & & \\
\hline Salt added at table: No & 47 & & & 62 & & \\
\hline Yes & 53 & & & 38 & & \\
\hline
\end{tabular}

The mean urinary Na excretion for the whole population was 155 (SD 63.1) mmol/d, which is equivalent to 8.9 (SD 3.6) g salt/d and the urinary $\mathrm{K}$ excretion was 82.3 (SD 27.9 ) $\mathrm{mmol} / \mathrm{d}$. Only $1.6 \%$ of men and $7.8 \%$ of women (4.8\% of the whole population) met the target of $<70 \mathrm{mmol} \mathrm{Na}$ (4 g salt)/d, which is recommended for reduced incidence of chronic disease, and only $10.9 \%$ of men and $30.9 \%$ of women ( $21.3 \%$ for whole population) had intakes $<100 \mathrm{mmol} \mathrm{Na}(6 \mathrm{~g}$ salt)/d. Those who reported adding salt in cooking had a $19 \%$ higher Na excretion than those who did not (159 (SD 64.3) mmol/d v. 129 (SD 48.8) mmol/d; $P<0.001$ ), but there was no difference between those who did or did not add salt at the table $(158$ (SD 66.5) mmol/d $v .153$ (SD 60.4) mmol/d). Use of salt in cooking differed by ethnic group: $62 \%$ Australian, New Zealand and other (37\% sample) used salt in cooking and this percentage was less than that for participants from an Italian background 97 (32\% sample) and a Greece background 98 (30\% sample; $P<0.001)$.

To achieve the population target of $6 \mathrm{~g} / \mathrm{d}$ a reduction in the $\mathrm{Na}$ content of manufactured foods should be coupled with an educational campaign with messages to reduce discretionary salt use, particularly in cooking, with reference to specific cultural cooking practices.

1. He FJ \& Macgregor GA (2002) J Hum Hypertens 16, 761-770.

2. National Health and Medical Research Council (2006) Nutrient Reference Values for Australia and New Zealand Including Recommended Dietary Intakes. Canberra: National Health and Medical Research Council. 